\title{
Facile Preparation of Lightweight and Robust Polybenzoxazine foams
}

\author{
Shuai Zhang, ${ }^{\S, a}$ Jiapeng Zong, ${ }^{\S, a}$ Qichao Ran, ${ }^{*, a}$ Yi Gu ${ }^{\mathrm{a}}$
}

${ }^{a}$ College of Polymer Science and Engineering, Sichuan University, State Key Laboratory of Polymer Materials Engineering, Chengdu 610065, China

$\S$ These two authors contribute equally to this work and should be considered as co-first authors.

\section{Corresponding Author}

*(Q.R.) ranqichao@scu.edu.cn

\section{Content}

Figure S1. SEM micrographs of precipitates prepared from BA-a/hexamethylenediamine in methanol/chloroform with molar ratio of 1.5:1 $\left(\mathrm{A}_{1}, \mathrm{~A}_{2}\right.$ and $\left.\mathrm{A}_{3}\right)$ and $1: 1 \quad\left(\mathrm{~B}_{1}, \mathrm{~B}_{2}\right.$ and $\left.\mathrm{B}_{3}\right)$ ..p1

Figure S2. DSC thermograms of polybenzoxazine foams A-20 and F-20 .................................... 2

Figure S3. DSC thermograms of polybenzoxazine foams.....................................................p2

Figure S4. TMA thermogram of

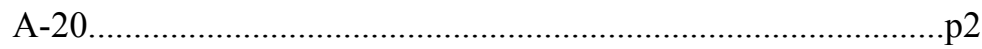

Figure S5. Compressive stress-strain curves of A-20 .............................................................. 3

Figure S6. Apperance of A-20 during compression test (A) and after breakage (B)......................p3

Figure S7. Apperance of foams before (A) and after (B) compression tests................................p3 


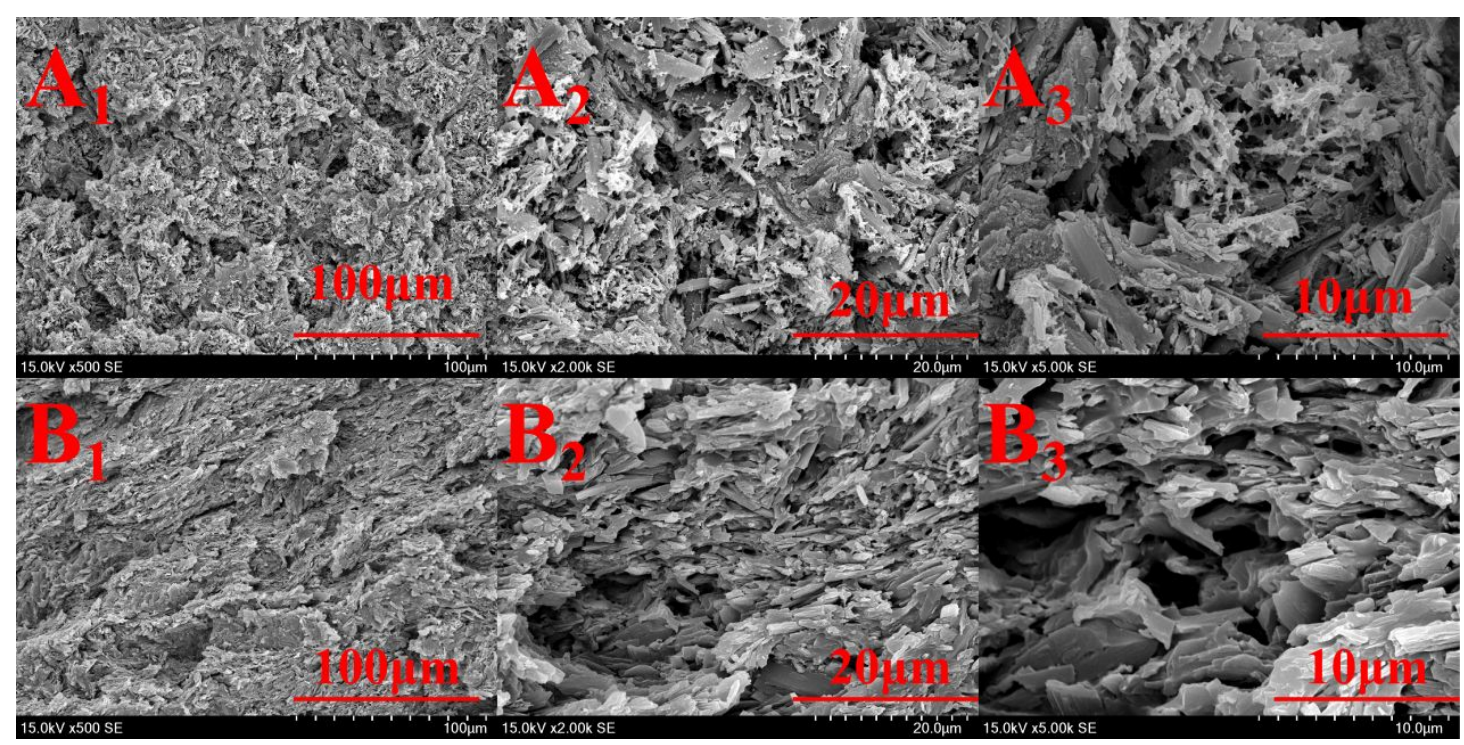

Figure S1. SEM micrographs of precipitates prepared from BA-a/hexamethylenediamine in methanol/chloroform with molar ratio of 1.5:1 $\left(\mathrm{A}_{1}, \mathrm{~A}_{2}\right.$ and $\left.\mathrm{A}_{3}\right)$ and $1: 1\left(\mathrm{~B}_{1}, \mathrm{~B}_{2}\right.$ and $\left.\mathrm{B}_{3}\right)$.

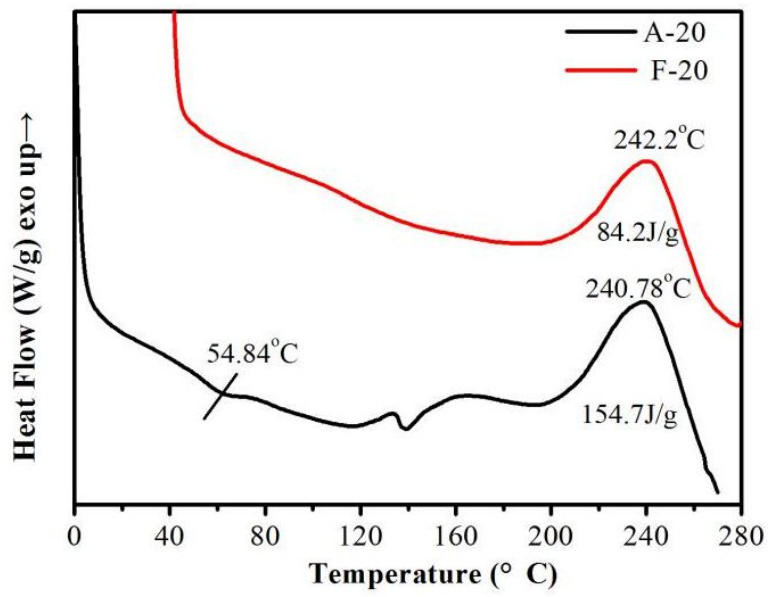

Figure S2. DSC thermograms of polybenzoxazine foams A-20 and F-20. 


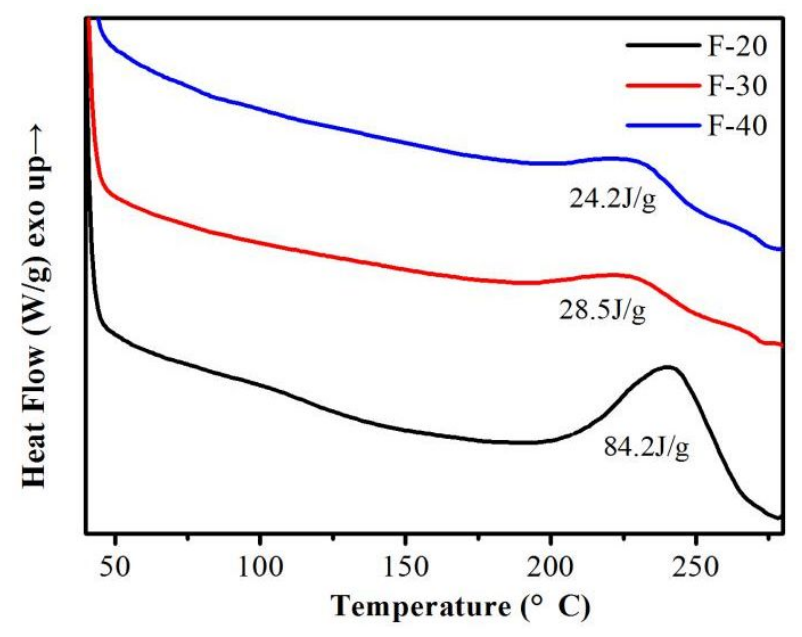

Figure S3. DSC thermograms of polybenzoxazine foams.

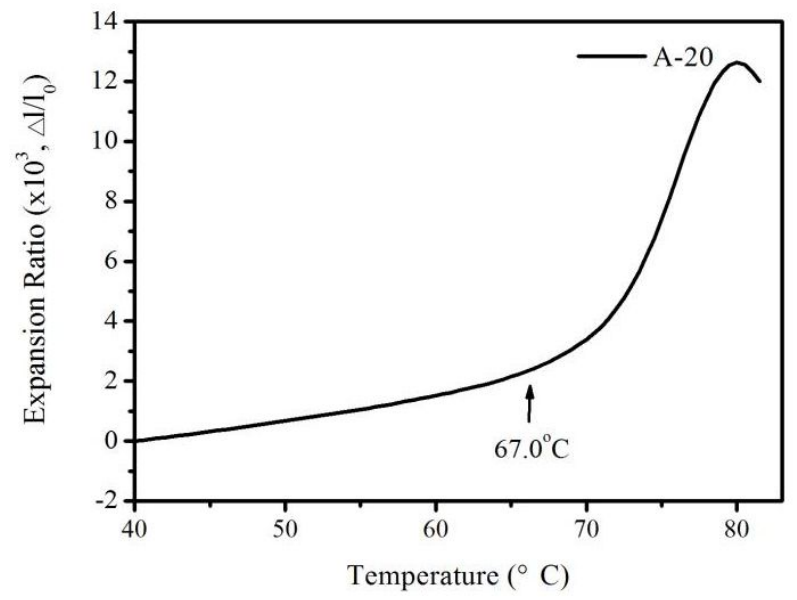

Figure S4. TMA thermogram of A-20.

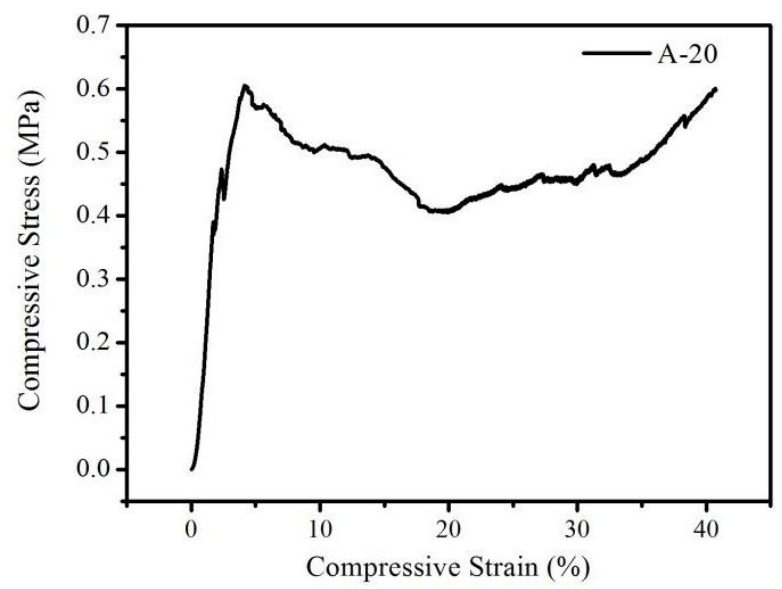


Figure S5. Compressive stress-strain curves of A-20.

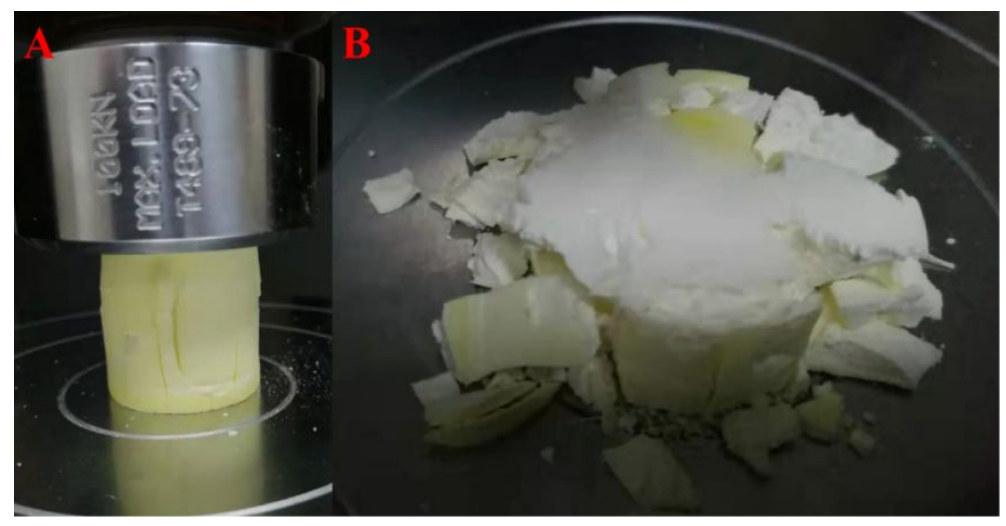

Figure S6. Apperance of A-20 during compression test (A) and after breakage (B).

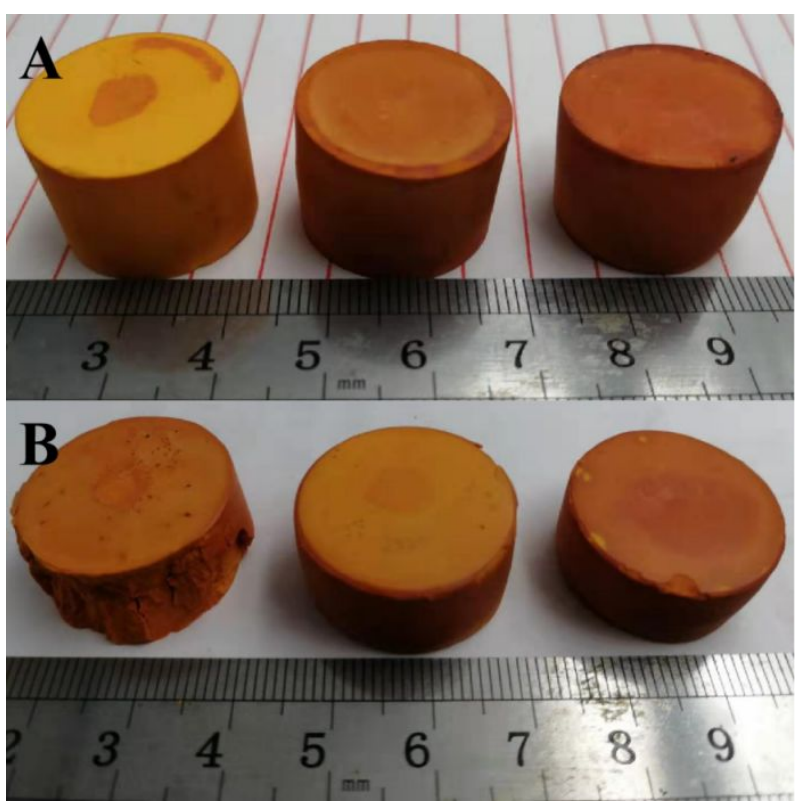

Figure S7. Apperance of foams before (A) and after (B) compression tests. 